\title{
The Role of the Family Network When Raising a Child with a Disability in Low- and Middle-Income Countries
}

\author{
Andrea Bizzego ${ }^{1}\left(\mathbb{D}\right.$, Mengyu $\operatorname{Lim}^{2}(\mathbb{D})$, Dagmara Dimitriou ${ }^{3}(\mathbb{D})$ and Gianluca Esposito $^{1,2,4, *(\mathbb{D})}$ \\ 1 Department of Psychology and Cognitive Science, University of Trento, 38068 Rovereto, Italy; \\ andrea.bizzego@unitn.it \\ 2 Psychology Program, School of Social Sciences, Nanyang Technological University, \\ Singapore 639798, Singapore; mengyu.lim@ntu.edu.sg \\ 3 Sleep Education and Research Laboratory (SERL), UCL Institute of Education, London WC1H 0AA, UK; \\ d.dimitriou@ucl.ac.uk \\ 4 Lee Kong Chian School of Medicine, Nanyang Technological University, Singapore 639798, Singapore \\ * Correspondence: gianluca.esposito@ntu.edu.sg or gianluca.esposito@unitn.it
}

Citation: Bizzego, A.; Lim, M.;

Dimitriou, D.; Esposito, G. The Role of the Family Network When Raising a Child with aDisability in Low- and Middle-Income Countries. Disabilities 2021, 1, 58-68. https://doi.org/ 10.3390/disabilities1010005

Received: 28 January 2021 Accepted: 15 March 2021 Published: 19 March 2021

Publisher's Note: MDPI stays neutral with regard to jurisdictional clai$\mathrm{ms}$ in published maps and institutional affiliations.

Copyright: (C) 2020 by the authors. Licensee MDPI, Basel, Switzerland. This article is an open access article distributed under the terms and conditions of the Creative Commons Attribution (CC BY) license (https:// creativecommons.org/licenses/by/ $4.0 /)$.

\begin{abstract}
Family plays a role in supporting child development, by facilitating caregiving and other parental practices. Low- and middle-income families typically have a complex structure with many relatives living together in the same household. The role of family and family complexity in the caregiving of children with disabilities is still unknown. In this study, we use data from $N=22,405$ children with severe $(N=876)$ and mild or no disability $(N=21,529)$ from a large dataset collected in the 2005-2007 Multiple Indicator Cluster Survey. In particular, we adopt PageRank, a well-known algorithm used by search engines, to quantify the importance of each child in the family network. We then analyze the level of caregiving the child received in light of the child's importance and developmental status, using a generalized linear model. Results show a main effect of child's importance and of the interaction of child's importance and developmental status. Post hoc analysis reveals that higher child importance is associated with a better caregiving outcome only for children with mild or no disability.
\end{abstract}

Keywords: developmental disabilities; low- and middle-income countries; caregiving; family

\section{Introduction}

The African parenting adage often goes "it takes a village to raise a child", and this proverb continues to hold wisdom in modern day parenting. Due to the intensive nature of parenting, which refers to the strenuous process of raising another human being into independence and adulthood [1], parents and caregivers tend to create networks with the extended family [2-5], educators [6], and healthcare professionals [7], among other individuals and communities to ensure their child's holistic development. The interaction between various stakeholders in child development is succinctly captured by Bronfenbrenner's ecological systems theory, which posits a nested structure of micro- and macro-systems in influencing child development [8]. According to the ecological systems theory, the micro-system consists of the most direct, bi-directional relationships a child has with their immediate environment. Of these relationships, and especially for children of preschool age and below who spend the majority of their hours at home [9,10], the relationship dynamics of the child and their family members are of utmost importance.

Generally, having the support of one's family members in the process of parenting allows for higher caregiving quality, which is also related to more positive child outcomes, such as greater attachment security [11] and decreased externalizing behavior [12]. The presence of extended family members has also been conceptualized as a protective factor of family stress [13] and as altruistic actors to increase the resilience and survival of both the child and the family [14]. 
In the context of poverty, the relation between family and parenting is crucial, as parents need to rely on additional avenues of resources, manpower, and knowledge from other family members [5]. The presence of extended family members also moderates parental decisions in caregiving, such as in accepting kin-provided child care [3,4]. The loss of extended family members as a parenting resource has been linked to several adverse outcomes such as higher rates of child abuse [15] and decreased family cohesion [16], as well as poorer social competence and mental health in the child $[3,16]$.

The presence or absence of the support from other family members may play an even bigger role if the child has developmental disabilities (DDs). For the purposes of this study, a DD is defined as delayed development or impairment of the child's physical, learning, language, or behavioral capabilities [17]. Parents of children with DDs often experience greater parenting stress [18,19] and poorer psychological coping [20], among other negative outcomes [21]. At the same time, greater challenges of raising a child with a DD and its associated parenting effects are also related to worse child outcomes such as poorer social skills [22]. A model proposed by Armstrong and colleagues [13,23] integrates family processes, social support, quality of parenting, and child outcomes such as socioemotional and behavioral issues. In this model, social support consists of both kin and non-kin sources and serves as a mediating factor between other environmental factors and eventual family well-being and child outcomes. However, it is acknowledged that there is scarce understanding about how social support functions in the context of child DDs or with socioemotional difficulties, which is therefore not well integrated into both assessment and intervention in such exceptional situations. Additionally, social support in Armstrong et al.'s model [13] does not disambiguate between the support that originates from the parents' or caregivers' family, community, or peers, which is particularly important especially in the context of cultural differences in the living arrangements of households, where households of non-Western cultures typically consist of more than a single nuclear family (i.e., parents or caregiver and child(ren) only [24]) [3,5,25], thereby increasing the likelihood of family support originating disproportionately from other family members over other sources.

The lack of studies about how extended families interact in parenting, and especially in the case of child DDs, disproportionately affects families and households residing in non-Western cultures, typically lower income regions of the world. This seems in contrast with the fact that the incidence of DD cases is higher in low- and middle-income countries (LMICs) with respect to high-income countries [26-30]. Moreover, low-income families tend to experience more negative outcomes due to greater parenting stress [31]. Focusing on non-Western cultures is therefore a critical aim, to investigate differences in attitudes towards child DDs or in parenting style and functioning [32-34], as well as different causes of child DDs (e.g., intermarrying). In fact, the interest in cross-cultural studies in the area of child development has steadily grown [35] in order to understand how the vulnerable population of families of children with DDs may be uplifted globally [36,37].

Building on the previous studies focusing on DDs in LMICs [38,39], which focused on the different parenting strategies for children with different severities and types of DDs and other socioeconomic factors, this study considers the role of the family network in examining the issue of parental caregiving and child DDs.

\section{Aim of this Study}

Based on the above literature, this study aims at examining how parental caregiving can be influenced by the child's developmental status and family support in the context of LMICs. This study adopts an exploratory approach based on graph theory to determine the family network (and by extension, the extent of family support available to a child) and its relation with the severity of child DDs and the caregiving the child receives. 


\section{Methods}

\subsection{Dataset}

To address the research aim, this study relies on the Multiple Indicator Cluster Survey (MICS) [40]. Developed and executed by UNICEF, the MICS is a global, nationally representative, comprehensive household survey with more than 200 key indicators measuring physical and social conditions of well-being among men, women, and children. The third administration of the MICS (MICS3), used in this study (2005-2007), comprises three modular questionnaires designed to elicit information regarding the household and women and children under five years living in the household. Each module focuses on specific members of the household within a specific age range. A subset of these modules (described below) was selected in the current study to examine the relationship between the family network, child disabilities, and caregiving practices.

\section{Participants}

In the administration of the MICS, households were randomly selected for participation by using a hierarchical process that began from census enumeration areas, subsequently narrowed down to segments in each area, and finally to particular households within each segment [41]. Participants considered in this study were those who completed all the modules specified in the sections below. However, the target age ranges of each module differed: the Child Disabilities module examines children aged between 2 and 9 years, whereas the modules about parental caregiving target children aged under 5 years. As there is an overlap in the age ranges of the modules, the participants considered in this study were children aged between 2 and 5 years. Only one child for each household was chosen for the analysis using a random selection.

The final dataset was composed of 22,405 children (males = 11,471; age (months): mean $=40.8, \mathrm{SD}=9.9$ ) from 14 LMICs (see Table 1). During the data collection, ethics approvals were obtained separately at each site. The use of MICS3 data for the purposes of this study was approved by the Internal Review Board of Nanyang Technological University.

Table 1. Partitioning of the sample of the study into the 14 low- and middle-income countries. Income group data refer to the year 2019.

\begin{tabular}{ccccc}
\hline Country & $N$ & $N_{M N D}$ & $N_{S D D}$ & Income Group \\
\hline Albania & 666 & 647 & 19 & Upper-middle \\
Belize & 363 & 333 & 30 & Upper-middle \\
Cameroon & 2088 & 1984 & 104 & Lower-middle \\
Central African Republic & 3047 & 2748 & 299 & Low \\
Djibouti & 192 & 158 & 34 & Lower-middle \\
Georgia & 990 & 949 & 41 & Upper-middle \\
Ghana & 1051 & 1021 & 30 & Lower-middle \\
Lao PDR & 1697 & 1670 & 27 & Lower-middle \\
Mauritania & 1782 & 1696 & 86 & Lower-middle \\
Mongolia & 1801 & 1754 & 47 & Lower-middle \\
Mozambique & 4175 & 4134 & 41 & Low \\
Suriname & 973 & 926 & 47 & Upper-middle \\
Uzbekistan & 2433 & 2419 & 14 & Lower-middle \\
Yemen & 1147 & 1090 & 57 & Low \\
\hline
\end{tabular}

\subsection{Child Developmental Disabilities}

To measure the extent of disability of each child, a Child Disability Index (CDI) was computed based on information from the Child Disabilities module of the "Household Questionnaire". The Child Disabilities module is based on the "Ten Questions Questionnaire" (TQQ) that was answered by either the mother or primary caregiver of the child in question [42-44]. The TQQ includes a series of close-ended, dichotomous "yes/no" questions screening for the presence of any cognitive, language, sensory, or motor impairment 
in a child (see Table 2). The TQQ is broadly used for in-the-field studies and population screening, as it is a practical and swift method of obtaining easily comparable data on child disability across the globe [45]. However, the "Ten Questions" are unable to determine the severity of any disability $[46,47]$. In the present study, the CDI was derived by the count of positive answers associated with a disability out of the "Ten Questions" (Figure 1), with a larger CDI value reflecting the presence of multiple disabilities.

Table 2. "Ten Questions" that screen for child disabilities. The answer indicating disability column indicates the answer associated with a potential disability.

\begin{tabular}{cll}
\hline & Question & Answer Indicating Disability \\
\hline Q1 & Any serious delay sitting, standing, or walking? & Yes \\
\hline Q2 & $\begin{array}{l}\text { Does she/he have difficulty seeing in the daytime } \\
\text { or nighttime? }\end{array}$ & Yes \\
\hline Q3 & Does she/he appear to have difficulty hearing? & Yes \\
\hline Q4 & $\begin{array}{l}\text { When you ask her/him to do something, does she/he } \\
\text { seem to understand what you say? }\end{array}$ & No \\
\hline Q5 & Does she/he have difficulty walking or moving? & Yes \\
\hline Q6 & $\begin{array}{l}\text { Does she/he have fits, become rigid, or } \\
\text { lose consciousness }\end{array}$ & Yes \\
\hline Q7 & Does she/he learn to do things like others? & No \\
\hline Q8 & $\begin{array}{l}\text { Can she/he say recognizable words? } \\
\text { Q9A }\end{array} \begin{array}{l}\text { Can she/he name at least one object? (for 2 year } \\
\text { old children) }\end{array}$ & No \\
\hline Q9B & $\begin{array}{l}\text { Is her/his speech in any way different from normal? } \\
\text { (for children older than 2 years) }\end{array}$ & Yes \\
\hline Q10 & $\begin{array}{l}\text { Compared to other children, does she/he appear } \\
\text { mentally backward, dull, or slow? }\end{array}$ & Yes \\
\hline
\end{tabular}

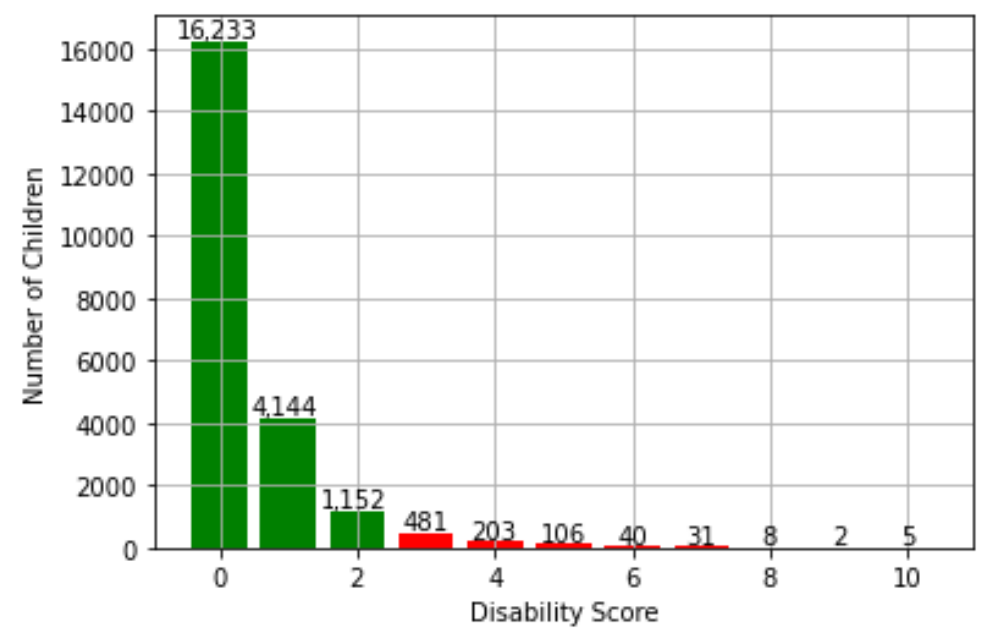

Figure 1. Distribution of the Child Disability Index (CDI). In red are the children that are categorized as having Severe Developmental Disabilities.

Only for the purposes of the post hoc analyses, children were categorized into two groups based on the severity of the disability condition. As the presence of multiple disabilities may indicate more severe conditions, a child with a CDI of at least 3 was classified as having severe disability (SDD; $N=876$ ), while a child with a CDI of less than 3 was classified as having mild or no disability (MND; $N=21,529)$. This threshold was 
determined empirically based on the balance between two considerations. Firstly, a lower threshold value was needed in order to have a statistically relevant number of children in the category of severe disability. On the other hand, a higher threshold value was needed to avoid including children with actual mild conditions in the category of severe disability. The decision of considering only two groups, MND with less severe cases and SDD with more severe cases, accounted for the fact that the TQQ is not a diagnostic tool, and lower scores might be due to a bias in the evaluation of the parent or other factors: a study on children from Bangladesh [42] reported that only $22 \%$ of children scoring positive to the TQQ were diagnosed with a serious disability condition. In this study, higher scores were assumed to be more likely associated with clinically relevant disability conditions.

\subsection{Household Listing}

The "Household Listing" module of the "Household" questionnaire was used to record the presence and relationships of different members of the household living together. In this study, these data were used to create the family graph of each household, to mathematically represent the parental relationships between all members of the household (Figure 2). First, the information about who, in the household, was the father and the mother of each household member was obtained, thus obtaining the "mother-father-child" triplets. Then the triplets were linked, also based on information from the indicator "Relationship to the household head" to link the floating nodes, whenever possible.

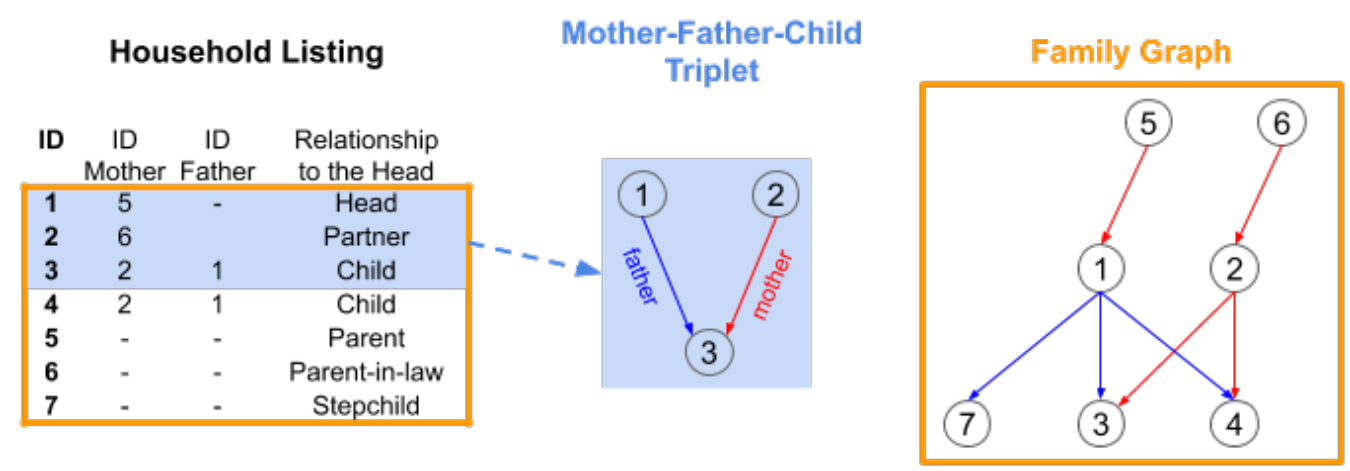

Figure 2. Steps to create the family graph, starting from information from the Household Listing module.

The PageRank score was computed for each node in the graph. PageRank considers both the number and quality of the linked nodes to quantify the importance of a node in a network. PageRank was initially developed to rank web pages in terms of their importance in the World Wide Web, and it is has broadly been used in scientific research, for instance in the study of various networks ranging from neuronal connections [48] to protein interactions $[49,50]$. In this study the PageRank score was used to quantify the importance of each child within the family graph (Figure 3). The creation of the family graphs and the computation of the PageRank score were based on the networkx Python package [51] (networkx.org, accessed on 18 March 2021).

\subsection{Caregiving}

To quantify the amount of caregiving that each child received, the "Caregiving" module from the questionnaire "Children Under 5" was used. The caregiving module in MICS3 has been used previously to investigate parental caregiving behavior [38,52-54].

The Caregiving" module determines who in the household was responsible for initiating six different activities of caregiving. Three activities are relevant to the child's cognitive development: "Read Books", "Tell Stories", "Spend Time/Name,Count,Draw", and three are activities relevant to the child's socio-emotional development: "Sing Songs", "Take Outside", "Play". For each activity, the module determines whether the child's mother, father, and/or other caregivers engage in the activity. For each activity the number of 
caregivers performing the activity (from 0: no one performs the activity; to 3 : the mother, the father and another caregiver perform the activity) was counted, to compute the total caregiving score as the sum of the counts across the six activities (Figure 3).
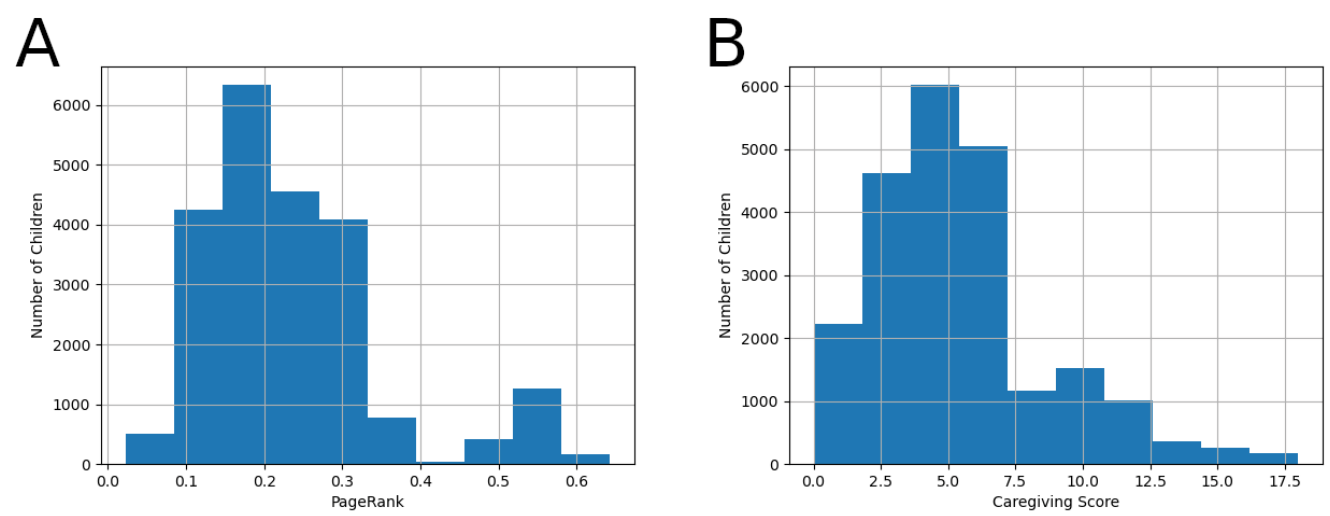

Figure 3. Distribution of the PageRank score (A) and Caregiving score (B).

\subsection{Parental Education}

The parental education (PE) for each child was obtained by computing the average education level of each child's parents. The reported education levels in the MICS reflect the different educational systems that are found in each country, and their specific characteristics. Similar to other studies [54,55], to obtain a consistent indication across the whole dataset, the reported education levels were recoded using an ordinal variable with 4 categories: no education (0), preschool/kindergarten (1), primary (2), secondary (3), and higher (4). Since the caregiving score is significantly associated with the PE $\left(r_{s}=0.29, p<0.001\right)$, to adjust the caregiving score for the PE, a generalized linear model (GLM) to predict the caregiving based on PE was fit. The residuals of the fitted GLM represent the total caregiving score adjusted for the PE, and were then used in the following analyses steps.

\subsection{Data Analysis}

A GLM was fitted to evaluate the effect of (a) disability (CDI), (b) child's importance in the family (child's PageRank score), and (c) their interaction on the level of caregiving received adjusted for PE. Post hoc analyses were then conducted to separately investigate the association between child's importance and adjusted caregiving. Spearman correlations were performed to assess the association between the adjusted caregiving score and the PageRank, for both the MND and SDD disability groups. Spearman correlation was selected instead of the Pearson correlation to allow for any monotonic relation between the variables.

\section{Results}

Results from the GLM (Table 3) indicate that the PageRank significantly predicts the amount of caregiving the child received. The main effect of CDI was not significant, but a significant effect of the interaction between CDI and PageRank emerged.

Post hoc Spearman correlations assessed whether the amount of caregiving the child receives is significantly associated with child's importance in the family graph. A significant association emerged for children with mild or no disability (MND group, $N=21,529$, $r_{s}=0.029, p<0.001$ ), but not for children with a severe developmental disability (SDD group, $N=876, r_{s}=-0.002, p=0.952$ ). 
Table 3. Coefficient of the CDI and PageRank of the general linear model with z- and $p$-values.

\begin{tabular}{ccccc}
\hline & Coefficient & SE & z-Score & $p$-Value \\
\hline Intercept & 0.130 & 0.001 & 152.94 & $<0.001$ \\
CDI & -0.001 & 0.001 & -1.53 & 0.125 \\
PageRank & -0.015 & 0.003 & -4.70 & $<0.001$ \\
CDI*PageRank & -0.006 & 0.003 & 1.97 & 0.049 \\
\hline
\end{tabular}

\section{Discussion}

In the current study, PageRank is used to obtain an objective measure of the importance of the child within the network of relationships between members of an household, in LMICs. The analyses revealed that the caregiving the child receives is associated with the importance of the child within the network, and, moreover, also depends on the interaction between the child's importance and DD status. The child DD alone resulted in a non significant predictor of the caregiving the receives. The significance of the child' importance within the family suggests that it is critical to consider the context of human networks and family structures, to better investigate child development and parenting practices.

On the other side, post hoc analyses conducted to investigate the interaction between child importance (PageRank) and disability revealed a significant association, albeit with small effect size, between the PageRank and the Caregiving score only for MND children. These findings suggest that additional factors should be considered alongside the family network, in particular for MND children.

This study sheds some light on how households allocate their resources among each household member, where a significant factor for this allocation depends on the relative importance of the particular member to the rest of the household. Although somewhat tangential in nature, the present finding is congruent with the resource dilution theory proposed by [56-60]. Originally studied in terms of intra-household resource allocation in economics and sociological research, the resource dilution theory posits that a larger household size would necessarily dilute the amount of finite resources available among a larger group of individuals, and has been found even in less tangible resources such as parental attention and companionship [61]. This may be the case for larger households typical in LMICs [3,5,25].

However, children of lower importance within a large household might not only experience diluted resources-in terms of lower quality or lower frequency of caregivingbut also be disproportionately allocated lesser caregiving resources as compared to other children with higher rankings. By providing a method to quantify child importance in a family, the approach adopted in this study could be useful to address open points about the allocation of resources, for instance the failure of achieving Pareto efficiency (maximum efficiency) in intra-household resource allocation among extended families [62].

On the other hand, the lack of significance in child DD status on received parental caregiving is contrary to past findings that child DD is a significant risk factor for parental neglect (i.e., low or absent caregiving) [63-67]. However, this finding may show that it is not simply the developmental status of a child that determines the eventual level of care received, but rather the implications of how child DD interacts with other factors, such as socioeconomic status and parental education level [39].

Lastly, a significant interaction effect emerged between PageRank metrics and child DD in the level of caregiving. While there was no difference in level of caregiving between high and low PageRank metrics for children with SDD, PageRank and caregiving showed a positive correlational relationship among children with MND. The interaction effect was further investigated in the post hoc analysis which suggested that only children with MND benefit from a higher importance in the family graph in terms of caregiving received. In other words, children with SDD with higher importance (High PageRank) do not receive significant more caregiving than children with SDD with lower importance (Low PageRank). Our interpretation involves the caregivers' self-stigma that children with more severe DD are harder to care for than children with MND [68]. This self-stigma 
might then result in a self-fulfilling prophecy that children with SDD face more problems, which in turn exacerbates negative child outcomes. Some examples of this self-stigma can manifest through caregivers' attitudes towards children with SDD. It has been found that parents and caregivers tend to have reservations towards including children with SDD in education programs [69], with parents tending to view children with disabilities as having lower socioemotional and behavioral skills $[68,70]$. While, in general, the importance of the child in the family affects the level of caregiving the child receives [62] as explained above, this self-stigma [68] might reduce or override this effect. However, additional studies are required to clarify the nature of this relation between child DD and importance in the family network: for instance, considering whether having more children serves as protective factor, and the role of siblings in the caregiving practices.

\subsection{Limitations}

The use of a household survey in determining PageRank metrics may not be flexible enough to account for the fluid and complex family structures of modern households [71-73]. For example, the household data would have difficulty in accounting for divorced families where family members may not be living together or have alternative, or temporary, living arrangements for the child [74,75]. Future studies may wish to make use of alternative family network data, such as social network methods proposed by [76] to confirm the present findings.

Additionally, our methodology did not use formal assessments of DD, which would have allowed for finer categorization of types of child DD, as well as a lower margin of error as compared to the "Ten Questions Questionnaire", as the tool tends to produce some false positives [42]. However, testing positive to the TQQ is significantly correlated to also being diagnosed with a disability [77]. The likelihood of false positives may also strengthen the results reported in this study between child SDD, family network and caregiving as it is now more likely that the significant finding was contributed by a smaller sample than is estimated.

Although the Caregiving Module of the MICS has been broadly used in the literature to investigate caregiving practices in LMIC [38,52-54], it mainly focuses on cognitive and socio-emotional activities. Other caregiving aspects or activities were not considered in this study.

Finally, it should be noted that only the third iteration of MICS was employed in this study, indicating only cross-sectional data without longitudinal follow-up to ascertain causality. An important consideration for making use of MICS3 was due to the fact that this was the last MICS study to include the "Ten Questions" to measure child DD. Future studies may wish to employ common pools of data in order to derive significant trends in this area over time, as some aspects of parenting and child disability may have changed in the last decades.

\subsection{Implications}

The present findings contribute to our understanding of how family networks and support are related to parental caregiving within the context of child disability status in LMICs. From the findings, we are able to elucidate some significant factors that may be considered when designing public policies and programs with the family and child disability in mind. Especially for LMICs where household sizes tend to be larger, studies of this nature would be able to contribute to the present understanding of complex family processes behind caregiving decisions of a vulnerable population.

Author Contributions: Conceptualization, A.B. and G.E.; Data curation, A.B.; Formal analysis, A.B.; Funding acquisition, G.E.; Investigation, A.B., D.D. and G.E.; Supervision, G.E.; Writing—original draft, M.L.; Writing - review \& editing, A.B., M.L., D.D. and G.E. All authors have read and agreed to the published version of the manuscript. 
Funding: This work was supported by the 2015 NAP Start-up Grant M4081597 (GE) from Nanyang Technological University Singapore and the Ministry of Education Tier-1 Grant (GE). A.B. was supported by a Post-doctoral Fellowship within MIUR program framework "Dipartimenti di Eccellenza" (DiPSCO, University of Trento, Italy). Computational resources were provided by the National Super Computing Center of Singapore (Project ID: 12001609; Computational study of Child Development in Low Resource Contexts).

Institutional Review Board Statement: The study was approved by the NTU Institutional Review Board (protocol code IRB-2020-04-040; date of approval: 09 May 2020 to 02 May 2023).

Informed Consent Statement: Ethics approvals and informed consents were handled in each site in which data were collected.

Data Availability Statement: Data can be obtained from UNICEF at mics.unicef.org (accessed on 18 March 2021).

Conflicts of Interest: The authors declare no conflict of interest. The funders had no role in the design of the study; in the collection, analysis, or interpretation of data; in the writing of the manuscript, or in the decision to publish the results.

\section{References}

1. Brooks, J.B. The Process of Parenting; ERIC: Washington, DC, USA, 1981.

2. Anyanwu, J.I.; Onuigbo, L.N.; Obiyo, N.O.; Eze, U.N.; Akaneme, I.N.; Aye, E.N.; Enyi, C.; Oforka, T.O.; Chigbu, B.C.; Ezenwaji, I.O.; et al. Parenting stress in families of children with autism spectrum disorder: The roles of the extended family. Glob. J. Health Sci. 2019, 11, 51-60. [CrossRef]

3. Tingvold, L.; Hauff, E.; Allen, J.; Middelthon, A.L. Seeking balance between the past and the present: Vietnamese refugee parenting practices and adolescent well-being. Int. J. Intercult. Relat. 2012, 36, 563-574. [CrossRef]

4. Brandon, P. An analysis of kin-provided child care in the context of intrafamily exchanges: Linking components of family support for parents raising young children. Am. J. Econ. Sociol. 2000, 59, 191-216. [CrossRef]

5. Zambrana, R.E.; Silva-Palacios, V.; Powell, D. Parenting concerns, family support systems, and life problems in Mexican-origin women: A comparison by nativity. J. Community Psychol. 1992, 20, 276-288. [CrossRef]

6. Easen, P.; Kendall, P.; Shaw, J. Parents and educators: Dialogue and development through partnership. Child. Soc. 1992, 6, 282-296. [CrossRef]

7. Johnson, C.P.; Kastner, T.A. Helping families raise children with special health care needs at home. Pediatrics 2005, 115, 507-511. [CrossRef] [PubMed]

8. Bronfenbrenner, U. The Ecology of Human Development; Harvard University Press: Cambridge, MA, USA, 1979.

9. US Bureau of Labour Statistics. 2018. Available online: https:/ /www.bls.gov/charts/american-time-use/activity-by-parent.htm (accessed on 15 May 2020).

10. Åman-Back, S.; Björkqvist, K. Parents' assessments of how much time they spend with their children at different ages. Psychol. Rep. 2004, 94, 1025-1030. [CrossRef] [PubMed]

11. Rosen, K.S.; Rothbaum, F. Quality of parental caregiving and security of attachment. Dev. Psychol. 1993, 29, 358. [CrossRef]

12. Rothbaum, F.; Weisz, J.R. Parental caregiving and child externalizing behavior in nonclinical samples: A meta-analysis. Psychol. Bull. 1994, 116, 55. [CrossRef]

13. Armstrong, M.I.; Birnie-Lefcovitch, S.; Ungar, M.T. Pathways between social support, family well being, quality of parenting, and child resilience: What we know. J. Child Fam. Stud. 2005, 14, 269-281. [CrossRef]

14. Kok, J.; Vandezande, M.; Mandemakers, K. Household structure, resource allocation and child well-being. A comparison across family systems. Tijdschr. Voor Soc. Econ. Geschied. 2011, 8, 76-101. [CrossRef]

15. Corse, S.J.; Schmid, K.; Trickett, P.K. Social network characteristics of mothers in abusing and nonabusing families and their relationships to parenting beliefs. J. Community Psychol. 1990, 18, 44-59. [CrossRef]

16. Leidy, M.S.; Guerra, N.G.; Toro, R.I. Positive parenting, family cohesion, and child social competence among immigrant Latino families. J. Fam. Psychol. 2010, 24, 252. [CrossRef] [PubMed]

17. Centers for Disease Control and Prevention. 2019. Available online: https://www.cdc.gov/ncbddd/developmentaldisabilities/ index.html (accessed on 15 May 2020).

18. Tomanik, S.; Harris, G.E.; Hawkins, J. The relationship between behaviors exhibited by children with autism and maternal stress. J. Intellect. Dev. Disabil. 2004, 29, 16-26. [CrossRef]

19. Hassall, R.; Rose, J.; McDonald, J. Parenting stress in mothers of children with an intellectual disability: The effects of parental cognitions in relation to child characteristics and family support. J. Intellect. Disabil. Res. 2005, 49, 405-418. [CrossRef] [PubMed]

20. Oelofsen, N.; Richardson, P. Sense of coherence and parenting stress in mothers and fathers of preschool children with developmental disability. J. Intellect. Dev. Disabil. 2006, 31, 1-12. [CrossRef] [PubMed]

21. Pelchat, D.; Lefebvre, H.; Perreault, M. Differences and similarities between mothers' and fathers' experiences of parenting a child with a disability. J. Child Health Care 2003, 7, 231-247. [CrossRef] 
22. Anthony, L.G.; Anthony, B.J.; Glanville, D.N.; Naiman, D.Q.; Waanders, C.; Shaffer, S. The relationships between parenting stress, parenting behavior and preschoolers' social competence and behavior problems in the classroom. Infant Child Dev. Int. J. Res. Pract. 2005, 14, 133-154. [CrossRef]

23. Armstrong, M.I. An Empirical Study: A Model of the Pathways between Social Support, Family Well Being, Parenting Quality, and Child Resilience. Ph.D Thesis, Memorial University of Newfoundland, St. John's, NL, Canada, 2003.

24. Hammel, E.A.; Laslett, P. Comparing household structure over time and between cultures. Comp. Stud. Soc. Hist. 1974, 16, 73-109. [CrossRef]

25. Laslett, P. Characteristics of the Western family considered over time. J. Fam. Hist. 1977, 2, 89-115. [CrossRef]

26. Boyle, C.A.; Boulet, S.; Schieve, L.A.; Cohen, R.A.; Blumberg, S.J.; Yeargin-Allsopp, M.; Visser, S.; Kogan, M.D. Trends in the prevalence of developmental disabilities in US children, 1997-2008. Pediatrics 2011, 127, 1034-1042. [CrossRef] [PubMed]

27. Leonard, H.; Petterson, B.; De Klerk, N.; Zubrick, S.R.; Glasson, E.; Sanders, R.; Bower, C. Association of sociodemographic characteristics of children with intellectual disability in Western Australia. Soc. Sci. Med. 2005, 60, 1499-1513. [CrossRef]

28. Department of Health and Social Care (UK Government). Valuing People: A New Strategy for Learning Disability for the 21st Century; HM Stationery Office: London, UK, 2001.

29. Magnus, P. Correlations between socioeconomic status, level of IQ and aetiology in mental retardation: A populationbased study of Norwegian children. Soc. Psychiatry Psychiatr. Epidemiol. 2000, 35, 12-18.

30. Drews, C.D.; Yeargin-Allsopp, M.; Decoufle, P.; Murphy, C.C. Variation in the influence of selected sociodemographic risk factors for mental retardation. Am. J. Public Health 1995, 85, 329-334. [CrossRef] [PubMed]

31. Noel, M.; Peterson, C.; Jesso, B. The relationship of parenting stress and child temperament to language development among economically disadvantaged preschoolers. J. Child Lang. 2008, 35, 823-843. [CrossRef]

32. Gaad, E. Cross-cultural perspectives on the effect of cultural attitudes towards inclusion for children with intellectual disabilities. Int. J. Incl. Educ. 2004, 8, 311-328. [CrossRef]

33. Wong, S.Y.; Wong, T.K.; Martinson, I.; Lai, A.C.; Chen, W.; He, Y. Needs of Chinese parents of children with developmental disability. J. Learn. Disabil. 2004, 8, 141-158. [CrossRef]

34. Fatimilehin, I.A.; Nadirshaw, Z. A cross-cultural study of parental attitudes and beliefs about learning disability (mental handicap). Ment. Handicap. Res. 1994, 7, 202-227. [CrossRef]

35. Bornstein, M.H. Handbook of Cultural Developmental Science; Psychology Press: London, UK, 2014.

36. Engle, P.L.; Black, M.M.; Behrman, J.R.; De Mello, M.C.; Gertler, P.J.; Kapiriri, L.; Martorell, R.; Young, M.E.; International Child Development Steering Group. Strategies to avoid the loss of developmental potential in more than 200 million children in the developing world. Lancet 2007, 269, 229-242. [CrossRef]

37. Pan, K.M. Children and the Millennium Development Goals: Progress Towards a World Fit for Children; UNICEF: New York, NY, USA, 2007.

38. Bizzego, A.; Lim, M.; Schiavon, G.; Setoh, P.; Gabrieli, G.; Dimitriou, D.; Esposito, G. Child disability and caregiving in low and middle income countries: Big data approach on open data. Res. Dev. Disabil. 2020, 107, 103795. [CrossRef]

39. Bizzego, A.; Lim, M.; Schiavon, G.; Esposito, G. Children with developmental disabilities in low-and middle-income countries: More neglected and physically punished. Int. J. Environ. Res. Public Health 2020, 17, 7009. [CrossRef]

40. UNICEF. Multiple Indicator Cluster Survey Manual 2005; UNICEF: New York, NY, USA, 2006.

41. Bornstein, M.H.; Putnick, D.L.; Bradley, R.H.; Deater-Deckard, K.; Lansford, J.E. Gender in low- and middle-income countries. In Monographs of the Society for Research in Child Development; Blackwell Publishing: Hoboken, NJ, USA, 2016 ; Volume 81.

42. Zaman, S.S.; Khan, N.Z.; Islam, S.; Banu, S.; Dixit, S.; Shrout, P.; Durkin, M. Validity of the 'Ten Questions' for screening serious childhood disability: Results from urban Bangladesh. Int. J. Epidemiol. 1990, 19, 613-620. [CrossRef] [PubMed]

43. Hendricks, C.; Lansford, J.E.; Deater-Deckard, K.; Bornstein, M.H. Associations between child disabilities and caregiver discipline and violence in low-and middle-income countries. Child Dev. 2014, 85, 513-531. [CrossRef]

44. Bornstein, M.H.; Hendricks, C. Screening for developmental disabilities in developing countries. Soc. Sci. Med. 2013, 97, 307-315. [CrossRef] [PubMed]

45. Gottlieb, C.A.; Maenner, M.J.; Cappa, C.; Durkin, M.S. Child disability screening, nutrition, and early learning in 18 countries with low and middle incomes: Data from the third round of UNICEF's Multiple Indicator Cluster Survey (2005-06). Lancet 2009, 374, 1831-1839. [CrossRef]

46. Mung'ala-Odera, V.; Meehan, R.; Njuguna, P.; Mturi, N.; Alcock, K.; Carter, J.; Newton, C. Validity and reliability of the 'Ten Questions' questionnaire for detecting moderate to severe neurological impairment in children aged 6-9 years in rural Kenya. Neuroepidemiology 2004, 23, 67-72. [CrossRef]

47. Christianson, A.; Zwane, M.; Manga, P.; Rosen, E.; Venter, A.; Downs, D.; Kromberg, J. Children with intellectual disability in rural South Africa: Prevalence and associated disability. J. Intellect. Disabil. Res. 2002, 46, 179-186. [CrossRef]

48. Fletcher, J.M.; Wennekers, T. From structure to activity: Using centrality measures to predict neuronal activity. Int. J. Neural Syst. 2018, 28, 1750013. [CrossRef]

49. Bánky, D.; Iván, G.; Grolmusz, V. Equal opportunity for low-degree network nodes: A PageRank-based method for protein target identification in metabolic graphs. PLoS ONE 2013, 8, e54204. [CrossRef] [PubMed]

50. Iván, G.; Grolmusz, V. When the Web meets the cell: Using personalized PageRank for analyzing protein interaction networks. Bioinformatics 2011, 27, 405-407. [CrossRef] [PubMed] 
51. Hagberg, A.A.; Schult, D.A.; Swart, P.J. Exploring Network Structure, Dynamics, and Function using NetworkX. In Proceedings of the 7th Python in Science Conference, Pasadena, CA, USA, 19-24 August 2008; pp. 11-15.

52. Bornstein, M.H.; Putnick, D.L.; Oburu, P.; Lansford, J.E.; Deater-Deckard, K.; Bradley, R.H.; Moriguchi, R.; Britto, P.R. Parenting, environment, and early child development in sub-Saharan Africa. In Handbook of Applied Developmental Science in Sub-Saharan Africa; Springer: Berlin/Heidelberg, Germany, 2017; pp. 15-53.

53. Cuartas, J.; Jeong, J.; Rey-Guerra, C.; McCoy, D.C.; Yoshikawa, H. Maternal, paternal, and other caregivers' stimulation in low-and-middle-income countries. PLoS ONE 2020, 15, e0236107. [CrossRef]

54. Jeong, J.; McCoy, D.C.; Fink, G. Pathways between paternal and maternal education, caregivers' support for learning, and early child development in 44 low-and middle-income countries. Early Child. Res. Q. 2017, 41, 136-148. [CrossRef]

55. Bornstein, M.H.; Putnick, D.L.; Bradley, R.H.; Lansford, J.E.; Deater-Deckard, K. Pathways among caregiver education, household resources, and infant growth in 39 low-and middle-income countries. Infancy 2015, 20, 353-376. [CrossRef] [PubMed]

56. Lindert, P.H. Fertility and Scarcity in America; Princeton University Press: Princeton, NJ, USA, 2015.

57. Downey, D.B. When bigger is not better: Family size, parental resources, and children's educational performance. Am. Sociol. Rev. 1995, 60, 746-761. [CrossRef]

58. Powell, B.; Steelman, L.C. Feeling the pinch: Child spacing and constraints on parental economic investments in children. Soc. Forces 1995, 73, 1465-1486. [CrossRef]

59. Blake, J. Family size and Achievement; University of California Press: Berkeleym CA, USA, 1989; Volume 3.

60. Blake, J. Family size and the quality of children. Demography 1981, 18, 421-442. [CrossRef]

61. Jensen, A.C.; Whiteman, S.D.; Bernard, J.M.; McHale, S.M. Family resource allocation after firstborns leave home: Implications for secondborns' academic functioning. Fam. Process. 2017, 56, 766-780. [CrossRef]

62. Dalton, M.; Hotz, J.; Thomas, D. Resources, Composition, and Family-Decision Making, Working Paper. 2014. Available online: http:/ / public.econ.duke.edu/vjh3/working_papers/FamDecisionMaking.pdf (accessed on 18 March 2021).

63. Leeb, R.T.; Bitsko, R.H.; Merrick, M.T.; Armour, B.S. Does childhood disability increase risk for child abuse and neglect? J. Ment. Health Res. Intellect. Disabil. 2012, 5, 4-31. [CrossRef]

64. Eshbaugh, E.M.; Peterson, C.A.; Wall, S.; Carta, J.J.; Luze, G.; Swanson, M.; Jeon, H.J. Low-income parents' warmth and parent-child activities for children with disabilities, suspected delays and biological risks. Infant Child Dev. 2011, 20, 509-524. [CrossRef]

65. Hibbard, R.A.; Desch, L.W.; Committee on Child Abuse and Neglect. Maltreatment of children with disabilities. Pediatrics 2007, 119, 1018-1025. [CrossRef]

66. Embry, R. Examination of risk factors for maltreatment of deaf children: Findings from a national survey. In Proceedings of the 7th International Family Violence Research Conference, Portsmouth, NH, USA, 22-25 July 2001.

67. Sullivan, P.M.; Knutson, J.F. Maltreatment and disabilities: A population-based epidemiological study. Child Abus. Negl. 2000, 24, 1257-1273. [CrossRef]

68. Li, X.; Lam, C.B.; Chung, K.K.H.; Leung, C. Linking parents' self-stigma to the adjustment of children with disabilities. Am. J. Orthopsychiatry 2019, 89, 212. [CrossRef]

69. Hilbert, D. Perceptions of parents of young children with and without disabilities attending inclusive preschool programs. $J$. Educ. Learn. 2014, 3, 49-59. [CrossRef]

70. Dyson, L.L. Children with learning disabilities within the family context: A comparison with siblings in global self-concept, academic self-perception, and social competence. Learn. Disabil. Res. Pract. 2003, 18, 1-9. [CrossRef]

71. Scanzoni, J. Household diversity. In Handbook of Contemporary Families: Considering the Past, Contemplating the Future; Sage: Los Angeles, CA, USA, 2004; p. 1.

72. Bien, W.; Marbach, J.; Neyer, F. Using egocentered networks in survey research. A methodological preview on an application of social network analysis in the area of family research. Soc. Netw. 1991, 13, 75-90. [CrossRef]

73. Wilson, P.; Pahl, R. The changing sociological construct of the family. Sociol. Rev. 1988, 36, 233-266. [CrossRef]

74. Furstenberg, F.F. The new extended family: The experience of parents and children after remarriage. In Remarriage and Stepparenting: Current Research and Theory; The Guilford Press: New York, NY, USA, 1987.

75. Pasley, K.; Ihinger-Tallman, M. Family boundary ambiguity: Perception of adult remarried family members. In Remarriage and Step-Parenting: Current Research and Theory; The Guilford Press: New York, NY, USA, 1987; pp. 228-240.

76. Widmer, E.D.; La Farga, L.A. Family networks: A sociometric method to study relationships in families. Field Methods 2000, 12, 108-128. [CrossRef]

77. UNICEF. Monitoring Child Disability in Developing Countries; UNICEF: New York, NY, USA, 2008. 